\title{
CLASSIFYING AND MAPPING OF VEGETATED AREA IN AL- BAHA REGION, SAUDI ARABIA USING REMOTE SENSING. I. EXTENT AND DISTRIBUTION OF GROUND VEGETATED COVER CATEGORIES.
}

\author{
Dr. Abdullah Saleh Biology Department, College of Sciences Al-Baha University Kingdom of Saudi \\ Al-Ghamdi \\ Arabia.
}

ABSTRACT Classifying and mapping vegetation is an important technical task for managing natural resources; the primary objective of the vegetation-mapping inventory is to produce high quality, standardized maps and associated data sets of vegetation. Satellite remote sensing has proven to be effective technology for mapping forest vegetation at the landscape to regional scale. In the remote sensing technique, vegetation density can be directly indicated by vegetation indices. Although there are several vegetation indices, the most widely used is the Normalized Difference Vegetation Index (NDVI), formulated by transforming raw satellite data into NDVI values, ranging from -1 to 1. NDVI enables the creation of images and other products that provide a rough measure of vegetation type, amount, and condition on land surfaces. The results show that medium to high density vegetation is mostly found in the central part of Al-Baha region separating the highlands and lowlands. The relationship study between NDVI and vegetation cover percentage in this study depicts an NDVI value of only $0.20-1.00$, which indicates that vegetation covers over $60 \%$ of Al-Baha. This is probably because vegetation here may not only comprise trees but also other plant forms such as herbs and shrubs. However, only $862.5 \mathrm{~km}^{2}(7.7 \%)$ of Al-Baha is covered with medium-high density vegetation, found mainly at the $6-15 \mathrm{~km}$ width horizontal central belt (in the Al-Mandaq, Al-Baha, and south Baljurashi districts) along a high, foggy mountainous plateau. Conversely, about $65 \%$ of Al-Baha region has very low to no vegetation density; vegetation is found extensively in the Tihama low plain towards the Red Sea and in the north-eastern desert plain. This study has provided a comprehensive report on vegetation mapping in the Al-Baha region.

KEYWORDS : Classifying, mapping, vegetated area, Al- Baha region, Saudi Arabia, remote sensing. Al-Mandaq, Baljurashi, Al-Qura, Al-Mekhwa, Al-Aqiq, Qelwah.

\section{INTRODUCTION.}

Classifying and mapping vegetation is an important technical task for managing natural resources, as vegetation provides a base for all living beings and plays an essential role in affecting global climate change, such as by influencing terrestrial $\mathrm{CO}_{2}$ (Xiagming et al. 2004). Vegetation mapping also presents valuable information for understanding natural and man-made environments by quantifying vegetation cover on local to regional scales at a given time point or over a continuous period. It is pertinent to acquire the current status of vegetation cover to initiate vegetation protection and restoration programs (Egbert et al. 2002; He et al. 2005).

Generally, the primary objective of the vegetation-mapping inventory is to produce high quality, standardized maps and associated data sets of vegetation and other land-cover occurring within forests. This information fills and complements a wide variety of resource assessment, forest management, and conservation needs.

Conventionally, vegetation mapping requires ground inventory carried out under severe climate conditions, such as dry air, high temperature, and strong sun, which affect human work capability, degrading result accuracy. In addition, it requires a lot of money, time, labor, equipment, and helpers. Hence, the estimation of vegetation density mapping at a relatively low cost, less laboriously, and with little time consumption is desirable. For the past three decades, vegetation inventory has become more cost-effective, less timeconsuming, and less labor-intensive due to remote sensing data. Satellite remote sensing has proven to be effective for mapping forest vegetation at a landscape to regional scale.

In the remote sensing technique, vegetation density can be directly indicated by vegetation indices, which are theoretically based on the observation that different vegetation surfaces reflect different types of light differently. Although there are several vegetation indices, the most widely used is the Normalized Difference Vegetation Index (NDVI), which is an index of plant "greenness" or photosynthetic activity. Photosynthetically active vegetation, in particular, absorbs most of the red light that hits it while reflecting much of the nearinfrared (NIR) light. Vegetation that is dead or stressed reflects more red light and less near-infrared light. Likewise, non-vegetated surfaces have much more even reflectance across the light spectrum (Marika et al., 2018).

NDVI values range from +1.0 to -1.0 . Areas of barren rock, sand, or snow usually show very low NDVI values (for example, 0.1 or less). Sparse vegetation such as shrubs and grasslands or senescing crops may result in moderate NDVI values (approximately 0.2 to 0.5 ). High
NDVI values (approximately 0.6 to 0.9 ) correspond to dense vegetation such as that found in temperate and tropical forests or crops at their peak growth stage (Anon, 2016).

A normal, healthy plant will absorb visible blue and red light and reflect visible green light, which is why it appears green to our eyes. In addition, plants also reflect NIR, as this type of light isn't actively used for the photosynthesis process (Figure 1).

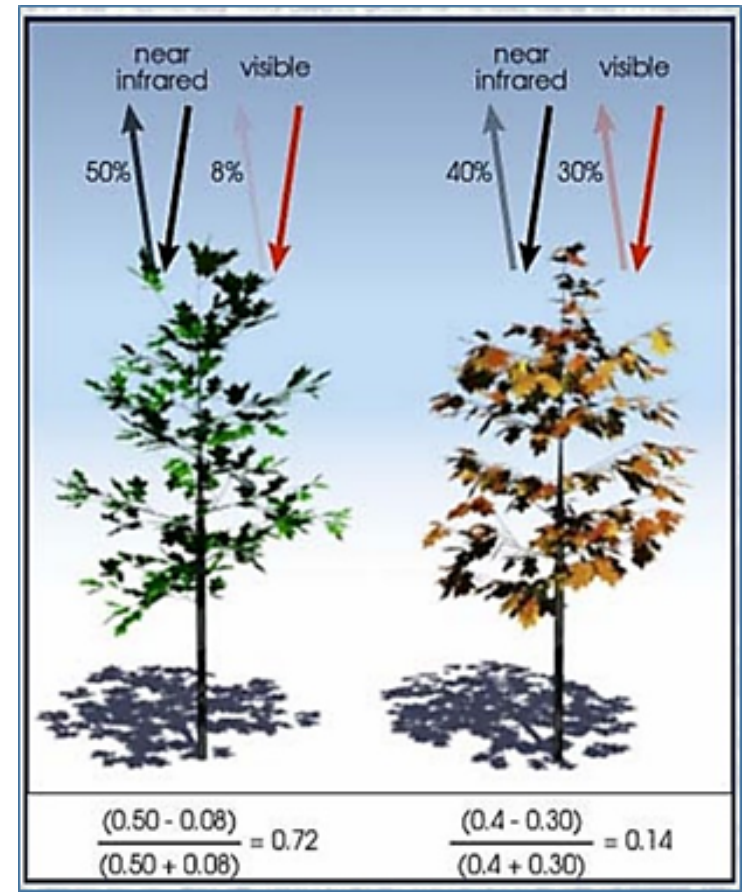

Figure 1: Pictorial representation showing lights absorbed and reflected differently with different chlorophyll content (source: Robin Simmon, 2000)

When a plant is weak or diseased, reflection of this NIR light is greatly decreased. Since red light is still being absorbed in the same way as in a healthy plant, a mathematical algorithm can calculate the difference in what is being reflected across a field of crops. Once calibrated and processed, it will become clear which plants are thriving and which are struggling (Yengoh G.T. et al., 2014). 
By transforming raw satellite data into NDVI values, researchers can create images and other products that give a rough measure of vegetation type, amount, and condition on land surfaces around the world. NDVI is especially useful for continental to global scale vegetation monitoring because it can compensate for changing illumination conditions, surface slope, and viewing angle. That said, NDVI does tend to saturate over dense vegetation and is sensitive to underlying soil color (Yengoh G.T. et al., 2014)

NDVI values can be averaged over time to establish "normal" growing conditions in a region for a given time of year. Further analysis can then characterize the health of vegetation in that place relative to the norm. When analyzed through time, NDVI can reveal where vegetation is thriving and where it is under stress, as well as changes in vegetation due to human activities such as deforestation, natural disturbances such as wild fires or changes in plants' phenological stage

\section{MATERIALAND METHOD.}

In this study, the technology used is satellite remote sensing. The following paragraph describes the material, data, and method applied.

\section{- Material and Data}

\section{In this project, the following software was used:}

- ERDAS Imagine 2014 - an image processing software

- ArcGIS ver 10.3 - a GIS software to do analysis information extracted from satellite image

- Data used in this project were:

- Satellite image LANDSAT-8 dated 15 May 2016 (resolution 30m x $30 \mathrm{~m}$ )

- Digital boundary of Al-Baha region and district

- Quickbird/SPOT (from Google Earth)

\section{Method}

This study involved three main components: data collection, data analysis, and field work. The overall workflow of this study is shown in Figure 2.

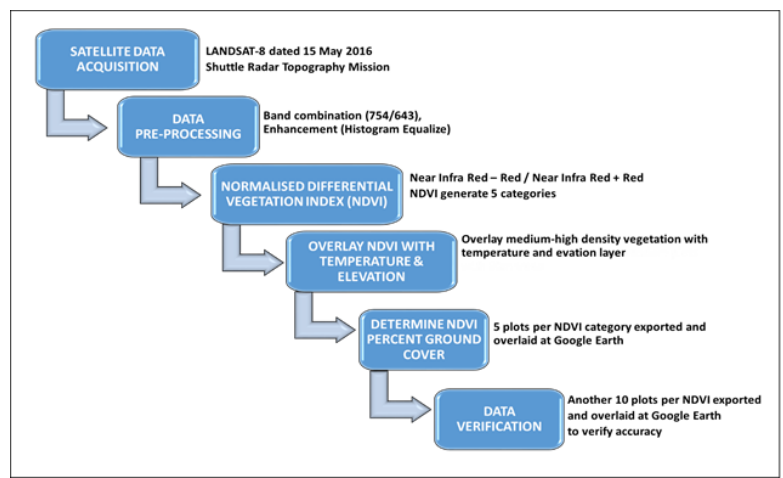

Satellite image LANDSAT-8 dated 15 May 2016 was used as the primary source for data extraction to identify the vegetated area in the Al-Baha region. Upon being downloaded from the USGS website, Image LANDSAT-8 was processed for NDVI to demarcate areas with vegetation or chlorophyll. Detailed activities of the workflow are shown in the next paragraph.

\section{Satellite Data Acquisition}

Remote sensing data acquired from the LANDSAT- 8 satellite imagery (15 May 2016) path/row 168/46 were downloaded from the United States Geological Survey (USGS) website. LANDSAT-8 images provide moderate-resolution imagery from 15-100 meters of the earth's land surface and polar regions. LANDSAT- 8 operates in the visible, near-infrared, short-wave infrared, and thermal infrared spectrums. LANDSAT- 8 captures more than 700 scenes a day. It consists of nine spectral bands with a spatial resolution of 30 meters for Bands 1 to 7 and 9 while band 8 is 15 meters.

\section{The LANDSAT- 8 bands are:}

Band 1 (ultra-blue $0.433-0.453 \mu \mathrm{m}), 0.680 \mu \mathrm{m}$ ),

Band 2 (blue $0.450-0.515 \mu \mathrm{m}$ ),

Band 3 (green 0.525-0.600 $\mu \mathrm{m}$ ),

Band $4($ red $0.630-0.680 \mu \mathrm{m})$,

Band 5 (near infrared $0.845-0.885 \mu \mathrm{m}$ ),

Band 6 (short infrared 1.560-1.660 $\mu \mathrm{m}$ ),

Band 7 (short infrared 2.100-2.300 $\mu \mathrm{m}$ ),
Band 8 (panchromatic $0.500-0.680 \mu \mathrm{m}$ ),

Band 9 (cirrus 1.360-1.390 $\mu \mathrm{m}$ ).

The approximate scene size is $170 \mathrm{~km}$ north-south by $183 \mathrm{~km}$ east-west (Roy et al., 2016)

\section{Satellite Image Pre-processing}

Image pre-processing is the process of making an image more interpretable for a particular application. It makes important features of raw, remotely sensed data more interpretable to the human eye. Image pre-processing includes data correction i.e. radiometric correction, geometric correction, and so on.

Remote sensing software ERDAS Imagine version 2014 was used to process the raw LANDSAT- 8 data including the radiometric correction, band combination, image enhancement, and other basic image processing systems for data analyzing. ERDAS Imagine is a remote sensing application with raster graphics editor abilities designed by ERDAS for geospatial applications. It is aimed mainly at geospatial raster data processing and allows users to prepare, display, and enhance digital images for mapping use in geographic information system (GIS) and computer-aided design (CAD) software. It is a toolbox allowing the user to perform numerous operations on an image and generate an answer to specific geographical questions (Hexagonspatial, 2016).

By manipulating imagery data values and positions, it is possible to see features that would not normally be visible and to locate geo-positions of features that would otherwise be graphical. The level of brightness or reflectance of light from the surfaces in the image can be helpful with vegetation analysis, prospecting for minerals etc. Other usage examples include linear feature extraction, generation of processing work flows (spatial models in Imagine), import/export of data for a wide variety of formats, orthorectification, mosaicking of imagery, stereo and automatic feature extraction of map data from imagery (Wikipedia). In this study, the image processing included band combination, geometric correction, and image enhancement and filtering (Hexagonspatial, 2016).

\section{Image Enhancement and Filtering}

The selection of suitable band combination is essential for LANDSAT8 by making enhanced images for visual interpretation. Removing blurring and noise, increasing contrast, and revealing details are examples of enhancement operations (Rapp, 1996). There is no ideal or best image enhancement because the results are ultimately evaluated by human beings, who make a subjective judgment as to whether a given image enhancement is useful (Jensen, 2005). In this project, images were enhanced using Histogram Equalize to contrast the different land uses.

\section{Histogram Equalization}

Histogram modeling techniques (e.g. histogram equalization) provide a sophisticated method for modifying the dynamic range and contrast of an image by altering that image such that its intensity histogram has a desired shape. Unlike contrast stretching, histogram modeling operators may employ nonlinear and nonmonotonic transfer functions to map between pixel intensity values in the input and output images. Histogram equalization employs a monotonic, non-linear mapping which re-assigns the intensity values of pixels in the input image such that the output image contains a uniform distribution of intensities (i.e. a flat histogram). This technique is used in image comparison processes (because it is effective in detail enhancement) and in the correction of non-linear effects introduced by, say, a digitizer or display system. This method is useful in providing a good overall stretch with imagery by preventing pixel values from being stretched to the extremes. (ArGIS, 2016)

Histogram Equalization (HE) enhancement increases the global contrast of many images, especially when the usable data of the image is represented by close contrast values. Through this adjustment, the intensities can be better distributed on the histogram. This allows for areas of lower local contrast to gain a higher contrast. Histogram equalization accomplishes this by effectively spreading out the most frequent intensity values. The method is useful in images with backgrounds and foregrounds that are both bright or both dark.

\section{Normalised Differential Vegetation Index (NDVI)}

The normalized difference vegetation index (NDVI) is the ratio of the difference between the near-infrared band (NIR) and the red band (R) and the sum of these two bands (Rouse Jr et al., 1974). 
The NDVI algorithm takes advantage of the fact that green vegetation reflects less visible light and more NIR, while sparse or less green vegetation reflects a greater portion of the visible and less near-IR. NDVI combines these reflectance characteristics in a ratio so that it gives an index related to photosynthetic capacity.

The range of values obtained is between -1 and +1 . Only positive values correspond to vegetated zones; the higher the index, the greater the chlorophyll content of the target. NDVI has been used to identify and interpret a range of phenology metrics that describe periodic plant life-cycle events and how these are influenced by seasonal and interannual variations in climate. So the duration of photosynthetic activity (identified using NDVI) can be interpreted to indicate the length of the growing season. The time of maximum NDVI corresponds to time of maximum photosynthesis. Seasonally integrated NDVI indicates photosynthetic activity during the growing season and the rate of change in NDVI may indicate speed of increase or decrease of photosynthesis. These metrics are influenced by several characteristics of the vegetation. One of the most important in remote sensing is the leaf area index (LAI) which refers to the projected area of leaves per unit of ground area (Ross, 1983).

The NDVI values vary according to the radiation absorption by the chlorophyll in the red spectral area and its reflectance in the NIR spectrum. These values are between -1 and +1 , corresponding to the consistency of the green vegetation. The ones close to +1 (light color) represent a higher consistency of the vegetation and are specific to the dense broadleaf forest. The ones close to -1 (dark color) represent the

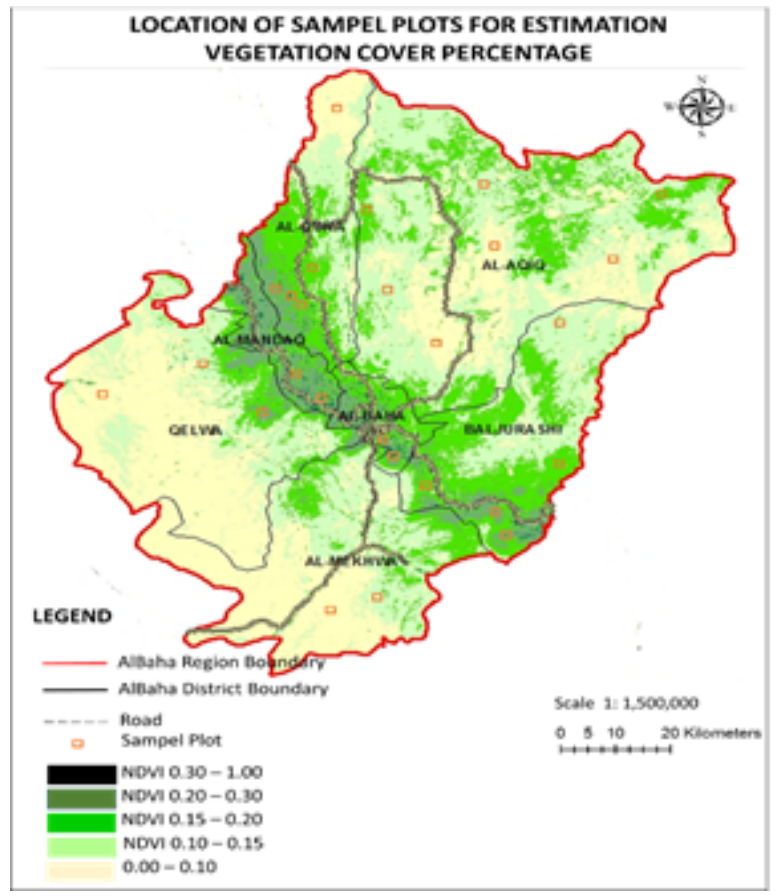

Figure 3. Location of Sample Plots for Estimation of Vegetation Cove

\section{Accuracy Assessment}

Data verification was conducted on plots randomly selected according to stratified NDVI categories of high, medium, low, and very low density vegetated, along with none vegetated. Ten (10) quadrant plots of $30 \mathrm{~m} \mathrm{x}$ land with lack of vegetation, having visible soil or rock surface. The 0 value (intermediate color) is associated with grasslands. It is useful in the mapping of vegetation areas, types, health status, land use etc. The formula for calculating this index is:

\section{NDVI $=$ NIR - RED $/$ NIR + RED}

An NDVI is calculated using the reflectance of the red $(0.6-0.7 \mu \mathrm{m})$ and the NIR $(0.7-1.1 \mu \mathrm{m})$ bands. It is calculated by dividing the difference of the red and NIR responses by the sum of these two bands. This method has been used regularly since 1989 by the United States Forest Service and other organizations to monitor the relative vigor or "greenness" of an area (USGS, 2016).

\section{Estimate Ground Vegetation Cover}

NDVI has found a wide application in vegetative studies as it has been used to estimate crop yields, pasture performance, and rangeland carrying capacities among others. It is often directly related to other ground parameters, such as percent of ground cover, photosynthetic activity of the plant, surface water, LAI, and amount of biomass (Anon, 2016).

In this study, NDVI is related to the percent of ground cover. To understand the relationship, five quadrant plots of size $30 \mathrm{~m} \times 30 \mathrm{~m}$ at every NDVI category were randomly selected from the NDVI map, subsequently exported to Google Earth to be overlaid, and the vegetation cover percentage was estimated. The 25 plots will indicate the percentage range of vegetation cover. Figure 3 shows the location of plots selected

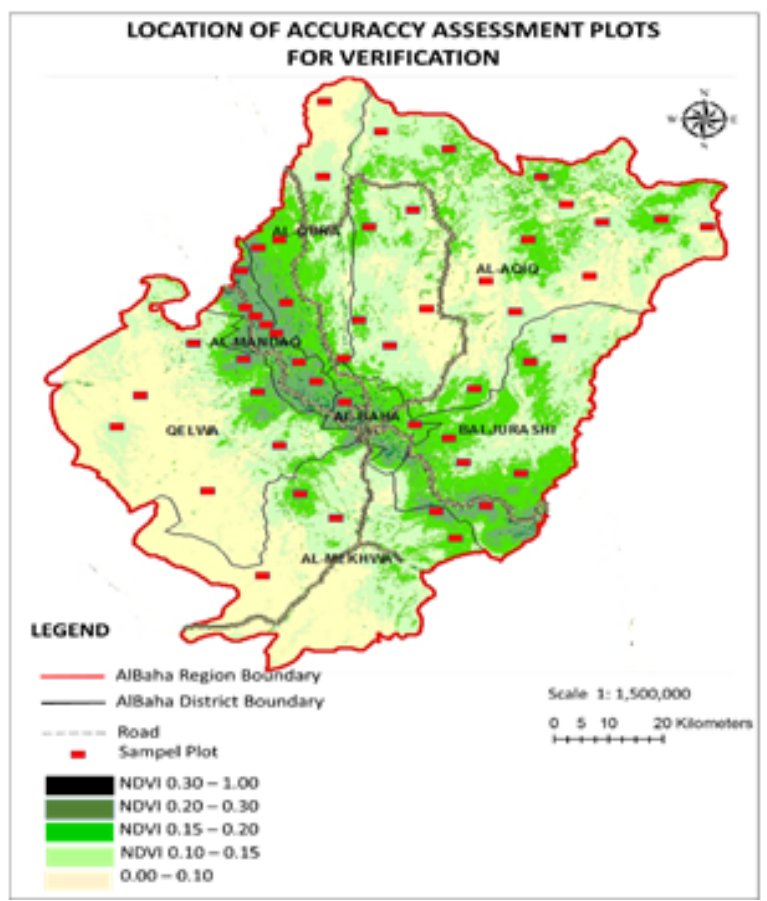

Figure 4: Location of Plots for Accuracy Assessment.

$30 \mathrm{~m}$ distributed evenly (different location from sample plots for vegetation cover percentage) were selected for each category, which makes a total of 50 plots (Figure 7).

$$
\begin{aligned}
& \text { Number correctly } \\
& \text { Total number of plots }
\end{aligned}
$$

These plots generated from ArcGIS were then overlaid on top of Quickbird/SPOT satellite image (resolution $0.5 \mathrm{~m} \times 0.5 \mathrm{~m}$ ) from Google Earth to estimate the percentage of vegetation cover. The number of plots which correctly matched with vegetation percentage cover was divided with the total number of plots (50) to calculate the percentage accuracy.

\section{RESULT}

This report provides five main results:

- Extent and distribution of vegetated categories in Al-Baha.
- Estimation of NDVI percent ground cover.

- Accuracy assessment.

\section{Extent and Distribution of Vegetated Categories in Al-Baha}

The NDVI map extracted from the LANDSAT- 8 satellite image depicts a total of $7,428.9 \mathrm{~km}^{2}(67.2 \%)$ of vegetated area in Al-Baha, comprising of high vegetation about $61.8 \mathrm{~km}^{2}(0.6 \%)$, medium vegetation $790.7 \mathrm{~km}^{2}(7.1 \%)$, low vegetation $2,400.6 \mathrm{~km}^{2}(21.7 \%)$, and very low vegetation $14,175.8 \mathrm{~km}^{2}(37.8 \%)$. Meanwhile the novegetation area is about $3,630.8 \mathrm{~km}^{2}(32.8 \%)$ (Table 1). 
Volume - 10 | Issue - 12 | December - 2020 | PRINT ISSN No. 2249 - 555X | DOI : 10.36106/ijar

Table 1: NDVI categories acreage at Al-Baha Region By District

\begin{tabular}{|c|c|c|c|c|c|c|c|c|c|c|c|}
\hline \multirow[t]{3}{*}{ District } & \multirow[t]{3}{*}{$\mathrm{Km}^{2}$} & \multicolumn{10}{|c|}{ NDVI Categories (density) } \\
\hline & & \multicolumn{2}{|l|}{ High } & \multicolumn{2}{|c|}{ Medium } & \multicolumn{2}{|l|}{ Low } & \multicolumn{2}{|c|}{ Very Low } & \multicolumn{2}{|l|}{ None } \\
\hline & & $\mathrm{Km}^{2}$ & $\%$ & $\mathrm{Km}^{2}$ & $\%$ & $\mathrm{Km}^{2}$ & $\%$ & $\mathbf{K m}^{2}$ & $\%$ & $\mathrm{Km}^{2}$ & $\%$ \\
\hline Al-Qura & $1,048.5$ & 9.2 & 0.9 & 128.4 & 12.3 & 373.1 & 35.6 & 328.3 & 31.3 & 209.5 & 0.2 \\
\hline Al-Aqiq & $3,667.3$ & 0.4 & 0.0 & 21.4 & 0.6 & 750.2 & 20.5 & $1,917.9$ & 52.3 & 977.4 & 0.3 \\
\hline Al-Mandaq & 360.8 & 23.0 & 6.4 & 246.8 & 68.4 & 81.8 & 22.7 & 8.6 & 2.4 & 0.6 & 0.0 \\
\hline M Al-ekhwa & $1,948.5$ & 2.5 & 0.1 & 41.5 & 2.1 & 239.8 & 12.3 & 665.6 & 34.2 & 999.2 & 0.5 \\
\hline Al-Baha & 298.1 & 16.6 & 5.6 & 106.3 & 35.6 & 150.7 & 50.5 & 19.8 & 6.6 & 4.7 & 0.0 \\
\hline Baljurashi & $1,504.6$ & 7.3 & 0.5 & 162.4 & 10.8 & 613.5 & 40.8 & 618.8 & 41.1 & 102.6 & 6.8 \\
\hline Qelwa & $2,232.0$ & 2.7 & 0.1 & 84.0 & 3.8 & 191.6 & 8.6 & 616.8 & 27.6 & $1,336.8$ & 59.9 \\
\hline TOTAL & $11,059.8$ & 61.8 & 0.6 & 790.7 & 7.1 & $2,400.6$ & 21.7 & $4,175.8$ & 37.8 & $3,630.8$ & 32.8 \\
\hline
\end{tabular}

Table 1 shows that Al-Mandaq district has the largest medium to high density vegetation zone with $269.8 \mathrm{~km}^{2}$, which covers $74.8 \%$ of the district. Meanwhile, Qelwa district has the most extensive of novegetation zones with $1,336.8 \mathrm{~km}^{2}(59.9 \%)$ and Al-Aqiq district has the most very-low vegetation zone with $1,917.9 \mathrm{~km}^{2}(52.3 \%)$. Maps at Figures 5, 6, 7, 8, and 9 illustrate the distribution of these NDVI categories.

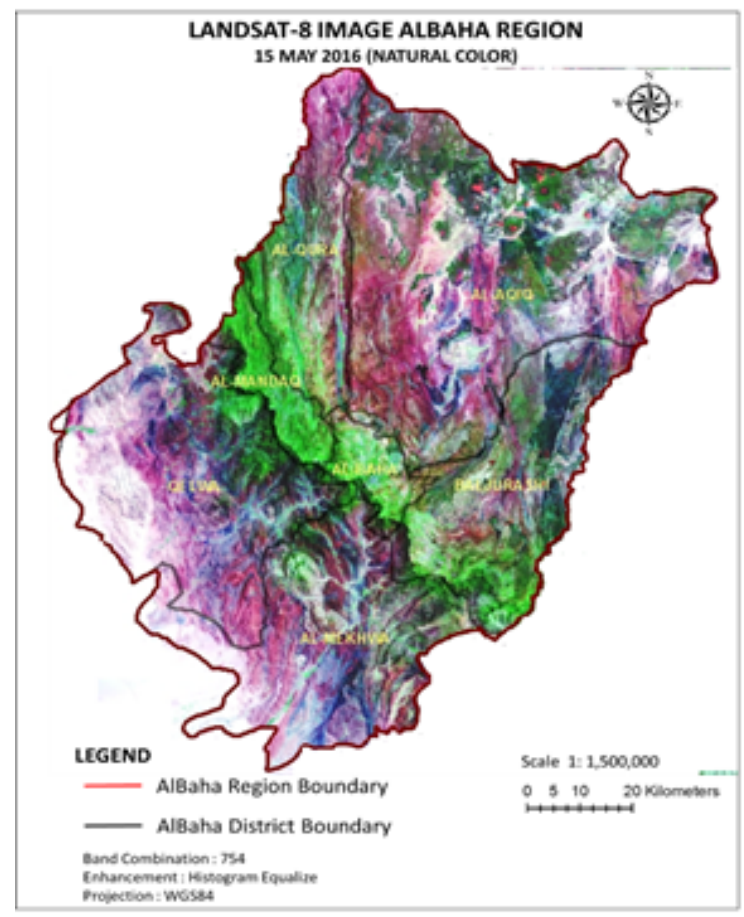

Figure 5 : Vegetation Density Map of Al-Baha Region (Natural Color). Bright green color indicates vegetation

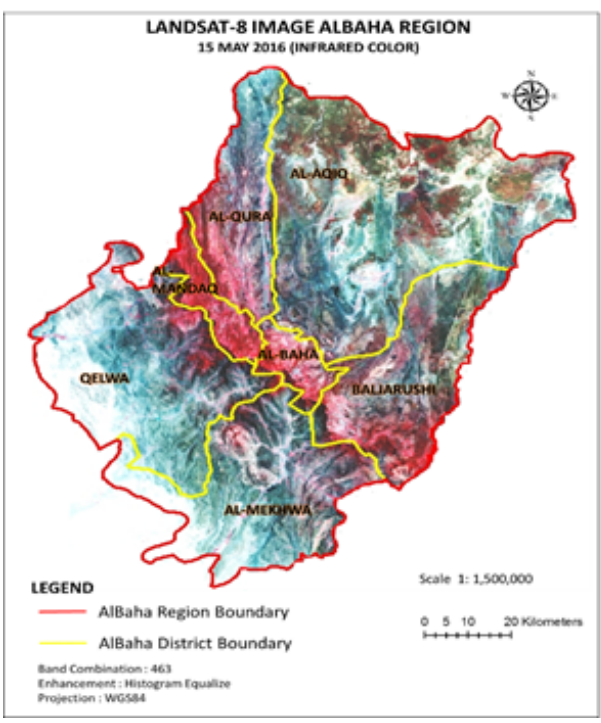

Figure 6 : Vegetation Density Map of Al-Baha Region (Infrared Color). Red color indicates vegetation presence

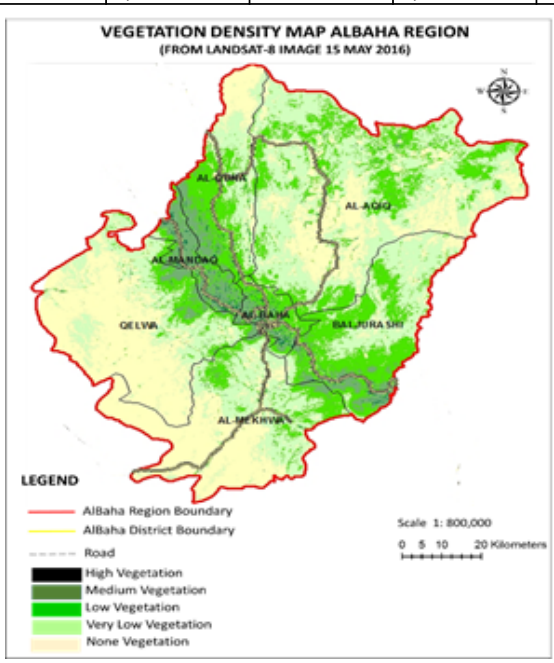

Figure 7: Vegetation Density Map of Al-Baha Region

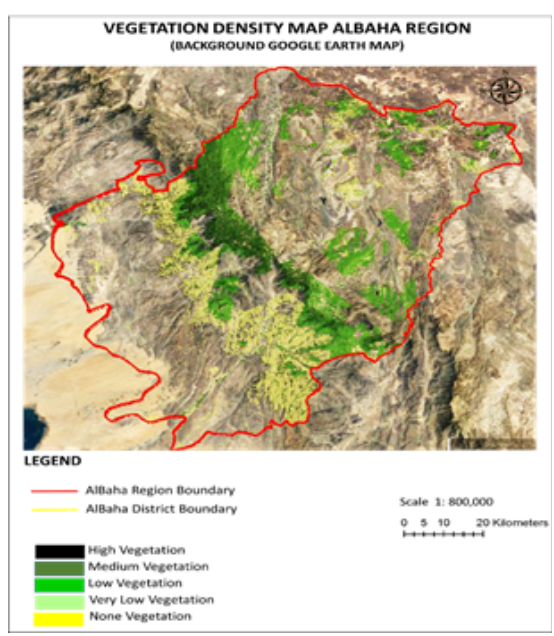

Figure 8:Vegetation map of Al-Baha Region on Google Earth Map

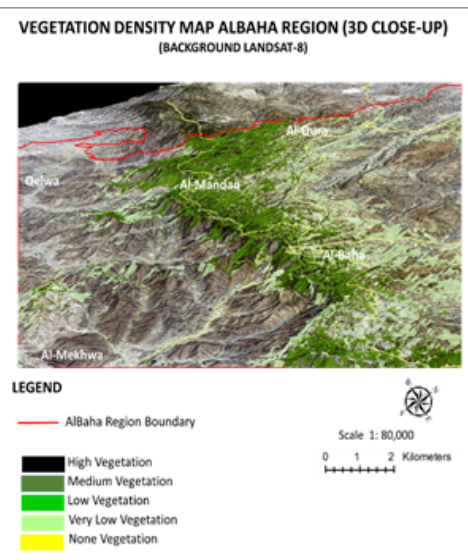

Figure 9 : Vegetation Density Map of Al-Baha Region on LANDSAT$8(3 D)$ 
Observations reveal that most of the high vegetated zones (high and medium NDVI) are located at the high plateau $3 \mathrm{~km}$ width horizontal belt central of Al-Baha, comprising Al-Mandaq and Al-Baha districts and the southern part of Baljurashi.

This area, totaling $860 \mathrm{~km}$ and covering only $7.7 \%$ of Al-Baha, is mainly located in the mountains above Aqabat Hizna and around Baljurashi and consists mostly of fog-affected seaward-facing mountain slopes. These are the zones where wild olives are most likely found, besides the abundance of juniper and acacia species. As reported by Al-Aklabi et al (2016), these landscapes support dense deciduous woodlands, dominated by the tree J. procera along with A. origena. The authors observed that as the influence of fog decreases further north-east or south-west, forests and woodlands are replaced by sparse woodlands or shrublands dominated by A. asak, A. tortilis, and A. ehrenbergiana. Beyond this, the vegetation becomes sparser and finally gives way to open semi-desert.

\section{Estimation of Percent Ground Cover for Each NDVI Category}

In this project, 25 quadrant plots of $30 \mathrm{~m} \times 30 \mathrm{~m}$ demarcated from the NDVI map were overlaid with Google Earth images to estimate vegetation cover percentage for each plot. Results from this Quickbird image of Google Earth shows that the highest NDVI value 0.30-1.00, categorized as high vegetation density, has a ground vegetation cover of more than $85 \%$, while the lowest NDVI value of $0.00-0.10$, categorized as none vegetation, has Google Earth ground vegetation cover of less than 10\%. Details of the observations are shown in Table 2

Table 2: Relationship between NDVI and Vegetation Cover Percentage

\begin{tabular}{|c|c|c|c|}
\hline Vegetation Density & NDVI value & Plots Correct & $\begin{array}{c}\text { Percentage } \\
\text { Correct (\%) }\end{array}$ \\
\hline High & $0.30-1.00$ & 10 & 100 \\
\hline Medium & $0.20-0.30$ & 9 & 90 \\
\hline Low & $0.15-0.20$ & 9 & 90 \\
\hline Very Low & $0.10-0.15$ & 10 & 100 \\
\hline None & $0.00-0.10$ & 10 & 100 \\
\hline TOTAL & & 48 & 96 \\
\hline
\end{tabular}

\section{Accuracy Assessment}

Accuracy assessments were conducted on fifty (50) plots of $30 \mathrm{~m} \times 30 \mathrm{~m}$ set up on Google Earth map with ten (10) plots distributed evenly for every vegetation density. At each plot, percentage vegetation cover was estimated. All images of these plots on Google Earth are from the Quickbird/SPOT satellite, which has a resolution of $0.5 \mathrm{~m} \mathrm{x} 0.5 \mathrm{~m} / 5 \mathrm{mx}$ $5 \mathrm{~m}$, high enough to discern the vegetation cover percentage in the AlBaha region.

Assessment was based on how accurately the vegetation density was interpreted from the LANDSAT-8 image to the vegetation cover percentage estimated from Google Earth Quickbird image. Results shows that out of 50 plots, 48 were correctly categorized, indicating the accuracy as $96 \%$, as shown in Table 3 .

Table 3: Vegetation Density in Relation with Number of Correct Plot

\begin{tabular}{|l|l|l|l|}
\hline $\begin{array}{l}\text { NDVI characteristic } \\
\text { interpretation }\end{array}$ & $\begin{array}{l}\text { Vegetation } \\
\text { density } \\
\text { category }\end{array}$ & $\begin{array}{l}\text { NDVI } \\
\text { value }\end{array}$ & $\begin{array}{l}\text { Google earth } \\
\text { vegetation } \\
\text { percentage cover } \\
(\mathbf{\%})\end{array}$ \\
\hline Dense vegetation & High & $0.30-1.00$ & $>85$ \\
\cline { 2 - 4 } & Medium & $0.20-0.30$ & $60-85$ \\
\hline Sparse vegetation & Low & $0.15-0.20$ & $30-60$ \\
\cline { 2 - 4 } & Very Low & $0.10-0.15$ & $10-30$ \\
\hline Barren rock/sand/snow & None & $0.00-0.10$ & $<10$ \\
\hline
\end{tabular}

\section{DISCUSSION}

The results show that the medium-high density vegetation is mostly found at the central part of Al-Baha region separating the highlands and lowlands. This project reaffirms the study conducted by many researches including by Al-Aklabi Abdullah, et al, (2016), who referred to the mountainous region of Al-Baha as the region with the most plant diversity in Saudi Arabia. Similarly, a study by El Juhany and M Aref (2012) also revealed that the highlands of Al-Baha have the highest numbers of trees. This includes the area from the Baha City to Gazzanah in the south, representing the areas of the highest elevations in the region (range between 1940 and $2366 \mathrm{~m}$. at sea water level).
The relationship between NDVI and the vegetation cover percentage in this study depicts that despite an NDVI value of only $0.20-1.00$, it has ground vegetation cover of above $60 \%$. This is probably because vegetation here may not only comprise trees but also other plant forms such as herbs and shrubs. This is in accordance to studies done by Aldhebiani, A. Y. and Howladar S. M. (2013) at Al-Baha, who observed that herbs dominated the vegetation of their study area $(51 \%)$, followed by shrubs $(20 \%)$, trees $(18 \%)$, and other individuals ranged shrubs to trees $(8 \%)$ and herbs to shrubs $(2 \%)$.

It was observed that the medium-high density vegetation zone also encompassed the Amdan forest which abounds in olive trees, Ara'r shrubs, and other natural vegetation along with Wadi Feig, which is encircled by a green valley littered with apricot, pomegranate and grape orchards. It also covers the Wadi Al Ageeg forest, which abounds in various fruit trees and tall lotus trees.

\section{CONCLUSION}

This project has provided a comprehensive report on vegetation mapping in the Al-Baha region as a base for the next phase of the 'Inventory and Mapping of the Wild Olive Tree in Al-Baha" project. Results obtained show that only $862.5 \mathrm{~km}^{2}(7.7 \%)$ of Al-Baha region is covered with medium to high density vegetation, mainly at the 6 $-15 \mathrm{~km}$ width horizontal central belt (in the districts of Al-Mandaq, AlBaha and south Baljurashi) along a high foggy mountainous plateau. This is the zone that will be emphasized for the following project, as observation shows that this zone has percent ground cover $>60 \%$ vegetation, indicating a high potential for wild olive tree presence. Conversely, about $65 \%$ of the Al-Baha region has very low-none density vegetation, mainly occurring extensively at the Tihama low plain towards the Red Sea and at the north-eastern desert plain.

\section{Acknowledgements}

This research was funded by chair of Sheikh Said Ben Ali Alangari for olives research at Al-Baha University, Al-Baha, Saudi Arabia. The author also acknowledges with thanks the Deanship of Scientific Research (DSP) at Al-Baha University for their technical support. Thanks extended to Geoprecision Tech Sdn Bhd (GPT) and Universiti Putra Malaysia (UPM) for their technical help.

\section{REFERENCES}

1. Al-Aklabi Abdullah, Abdul Wali Al-Khulaidi, Akram Hussain, Nageeb Al-Sagheer, (2016) Main vegetation types and plant species diversity along an altitudinal gradient of Al Baha region, Saudi Arabia Saudi Journal of Biological Sciences, Volume 23, Issue 6 , November 2016, Pages 687-697

2. Alaklabi, A., Arif, I. A., Bafeel, S. O., Alfarhan, A. H., Ahamed A., Thomas J., and Bakir, M. A. (2016), Nucleotide based validation of the endangered plant Diospyros mespiliformis (Ebenaceae) by evaluating short sequence region of plastid rbcL gene. Plant Omics J., 7 (2) (2014), pp. 102-107 (102). ISSN:1836-3644

3. Aldhebiani, A. Y., Howladar S. M. (2013), Floristic Diversity and Environmental Relations in Two Valleys, South West Saudi Arabia. International Journal of Science and Research (IJSR), 4(2), ISSN (Online): 2319 - 7064.

4. Anon. (2016), Understanding the Normalised Difference Vegetation Index. Website: www. fsnau.org/./Understanding the Normalized Vegetation Index NDVI.pdf.

ArcGIS (2016), Help-ArcGIS Resources. Website: resources. arcgis.com/en/help

5. Egbert, S. L., Park, S., Price, K. P., et al. (2002), Using conservation reserve program maps derived from satellite imagery to characterize landscape structure. Compu Electron Agric 37:141-56

7. El-Juhany, L. I., Aref, I. M. (2012), The Present Status of the Natural Forests in the Southwestern Saudi Arabia 2-Baha Forests. World Applied Sciences Journal (IS Journal) 20(2): 271-281. ISSN 1818-4952.

8. He, C. Q., Zhang, Y., Li, X., Li, P., Shi, (2005) Zoning grassland protection area using remote sensing and cellular automata modeling - A case study in Xilingol steppe grassland in Northern China. Journal of Arid Environments 63 (2005): 814-826.

9. Hexagonspatial (2016), Erdas Imagine. Website: http:// www. hexagongeospatial. Com / products / producer suite/erdas-imagine.

10. Loyd, C. (2016), LANDSAT-8 Bands, Landsat Science, NASA, http://landsat gsfc.nasa.gov/.

11. Rapp Carl Steven, (1996), "Image Processing and Image Enhancement, East Tennessee State University Johnson City, Texas.

12. Robin Simmon, (2000), Lead Data Visualizer and Information Designer (NASA)http:// earth observatory. NASA. Gov/Features / Measuring Vegetation/measuring vegetation 2.php Accessed 2.9.2014.

13. Ross, J. (1983), The radiation regime and architecture of plant stands. Boston: Junk, Journal of Ecology 71(1): 344-345.

14. Rouse, J.W., Haas, R.H., Schell, J.A. and Deering, D.W. (1974) Monitoring Vegetation Systems in the Great Plains with ERTS. Proceedings of 3rd Earth Resources Technology Satellite-1 Symposium, Greenbelt, NASA SP-351,3010-3017

15. Rouse, J.W., Haas, R.H., Schell, J.A. and Deering, D.W. (1973) Monitoring Vegetation Systems in the Great Plains with ERTS. 3rd ERTS Symposium, NASA SP-351, Washington DC, 10-14 December 1973,309-317

16. S.C. Freden, E. P. Mercanti, and M. Becker (Eds). Third Earth Resources Technology Satellite-1 Symposium, Volume 1: Technical Presentations, pp. 309-317, NASA SP351 NASA, Washington, D.C., pp. 309-317.

17. Roy D. K., Kovalskyy V., Zhang H. K., Vermote E. F., Yan L., Kumar S. S., Egorov A (2016). Characterization of Landsat-7 to Landsat-8 reflective wavelength and normalized difference vegetation index continuity. Remote Sensing of Environment, $185: 57-70$.

18. Simmon, R. (2000), Lead Data Visualizer and Information Designer (NASA) http: // earth observatory. nasa. Gov / Features / Measuring Vegetation/ measuring vegetation 2.php Accessed 2.9.2014. 
19. USGS (2016), Vegetation Indices - Remote Sensing Phenology, United States Geological Science. Website: http://phenology.cr.usgs.gov/ndvi foundation. Php.

20. Xiangming Xiaoa, Qingyuan Zhanga, Bobby Braswell, Shawn Urbanskib, Stephen Boles, Steven Wofsyb Berrien Moore III and Dennis Ojimac(2004). Modeling gross primary production of temperate deciduous broadleaf forest using satellite images and climate data. Remote Sensing of Environment 91:256-270.

21. Yengoh, G. T., Dent, D., Olsson, L., Tengberg, A. E., Tucker, C. J. III (2014). The use of Yengoh, G. T., Dent, D., Olsson, L., Tengberg, A. E., Tucker, C. J. III (2014). the Normalized Difference Vegetation Index (NDVI) to assess land degradation at multiple scales. Current status, future trends, and practical considerations, Springer Briefs in Environmental Science Print ISBN: 978-3-319-24110-4, Electronic ISBN: 978-3-319-24112-8. 